\title{
QUEBRAS CONTRATUAIS E DISPERSÃO DE SENTENÇAS
}

\author{
Christiane Leles Rezende e Decio Zylbersztajn ${ }^{1}$
}

CONTRACTUAL BREACHES AND SENTENCES DISPERSION

\section{RESUMO}

O PROBLEMA QUE MOTIVOU UM ESTUDO, O QUAL DEU ORIGEM A ESTE ARTIGO, FORAM AS QUEBRAS CONTRATUAIS POR PARTE DOS PRODUTORES RURAIS GERADAS PELA EXPRESSIVA ALTA DOS PREÇOS DA SOJA E AS CONSEQUENTES DISPUTAS JUDICIAIS. FORAM REALIZADAS ANÁLISES DESCRITIVA E ECONOMÉTRICA utilizando 161 Apelações do TRIBUnAL DE JUSTIÇA DE GOIÁS, E UMA PESQUISA QUANTITATIVA COM 70 PRODUTORES RURAIS. O ESTUdO CONSIDERA A HIPÓTESE DE QUE A INSTABILIDADE GERADA A PARTIR DAS DECISÕES JUDICIAIS ELEVA OS CUSTOS DE TRANSAÇÃO E AFETA AS DECISÕES DOS AGENTES PRIVADOS. FOI CONSTATADA LARGA DISPERSÃO ENTRE DECISÕES DE PRIMEIRA E SEGUNDA INSTÂNCIAS, BEM COMO ENTRE CÂMARAS CívEIS DO TJ. OS AGENTES ECONÔMICOS RELATARAM QUE AS ALTERAÇÕES NAS ESTRATÉGIAS DE SUPRIMENTO FORAM CENTRADAS NO AUMENTO DA EXIGÊNCIA DE GARANTIAS E REDUÇÃO DO NÚMERO DE CONTRATOS. O CONCEITO DE FUNÇÃO SOCIAL DO CONTRATO ESTÁ ASSOCIADO À ELEVAÇÃO DA INSTABILIDADE. DECORRERAM MAIORES CUSTOS DE TRANSAÇÃO, BEM COMO A ADOÇÃO DE SANÇÕES ECONÔMICAS POR PARTE DOS AGENTES PRIVADOS.

\section{PALAVRAS-CHAVE}

Contratos de soja, Decisões judicials, Ambiente INSTITUCIONAL

\begin{abstract}
THE PROBLEMS WHICH HAVE MOTIVATED A STUDY AND THIS ARTICLE WERE THE CONTRACTUAL BREACHES DURING AN EXPRESSIVE INCREASE OF PRICE AND THEIR JUDICIAL DECISIONS. DESCRIPTIVE AND ECONOMETRIC ANALYSIS HAVE BEEN CARRIED OUT ON 161 APPEAL JUDICIAL DECISIONS of GoIÁs COURT OF JUSTICE (BRAZIL) aND A QUANTITATIVE SURVEY WAS DONE WITH 70 FARMERS. THE STUDY HAS SUPPORTED THE HYPOTHESIS THAT A WEAK JUDICIARY INCREASES TRANSACTION COSTS AND DECREASES THE ECONOMIC DEVELOPMENT RATE. A LARGE DISPERSION OF COURT DECISIONS WAS FOUND BETWEEN THE FIRST AND APPEAL DECISION, AS WELL INSIDE THE SAME LEVEL. THE USE OF THE CONCEPT OF "SOCIAL ROLE OF CONTRACT" INSERTED A HIGH DEGREE OF INSTABILITY IN CONTRACTS THE EFFECTS OF COURT DECISIONS COULD BE REALIZED SUCH AS MORE REQUIREMENTS OF WARRANTIES AND THE REDUCTION IN THE NUMBER OF CONTRACTS. THOSE SOYBEAN PRODUCERS WHO DID NOT BREACH THEIR CONTRACTS ALSO HAVE BEEN NEGATIVELY AFFECTED BY THE STRATEGIC REACTIONS OF TRADING AND INDUSTRIES.
\end{abstract}

\section{KEYWORDS}

SOYBEAN CONTRACTS, JUDICIAL DECISIONS, INSTITUTIONAL ENVIRONMENTAL

\section{INTRODUÇÃO}

O comportamento do judiciário tem recebido atenção de estudiosos de estratégia, de modo especial a preocupação com os efeitos não esperados das decisões dos juízes sobre as organizações. O efeito das decisões do judiciário nas estratégias das organizações 
não tem sido estudado no Brasil, fato que motivou um estudo, e a produção deste artigo cujo teor analisa as decisões dos juízes e o subsequente impacto nas estratégias dos agentes econômicos.

O contrato de soja verde surgiu como um arranjo alternativo para obtenção de crédito em vista da limitada oferta de crédito agrícola. O termo refere-se à compra antecipada de soja por parte das indústrias esmagadoras e/ou tradings por meio de contratos.

Esse contrato surgiu com o objetivo de garantir o suprimento de produtos agrícolas para empresas processadoras e exportadoras de grãos, em especial a soja, gerando mecanismos de financiamento da atividade agrícola, seja na forma de financiamento direto dos produtores, seja na forma de fornecimento antecipado de insumos para os agricultores. Posteriormente, intensificou-se a modalidade do contrato sem a antecipação de recursos, com o objetivo de controlar a exposição ao risco de decisões judiciais favoráveis aos agricultores. Na maior parte dos casos o contrato é padronizado e os preços são fixados com base no mercado futuro da soja.

As partes, ao realizarem contratos de venda antecipada, podem ter objetivos diversos, como evitar o risco de oscilação de preço e/ou obter financiamento para a safra. Sob a óptica da economia das organizações, pode-se dizer que pelo menos dois elementos são transacionados: risco e/ou crédito.

O problema que motivou este artigo foram os conflitos entre as partes, decorrentes das quebras contratuais no momento da liquidação dos contratos e os mecanismos utilizados para a solução das disputas pós-contratuais, incluindo mas não se limitando aos mecanismos judiciais. Por quebras contratuais entende-se a falha total ou parcial na entrega do produto contratado. As safras de 2002/2003 e 2003/2004 foram particularmente problemáticas, pois o preço da saca de soja atingiu picos elevados no mercado spot, distanciando-se do preço que fora definido no contrato de compra e venda antecipada. Tal situação gerou incentivos para a quebra contratual e, em consequência, o ajuizamento de ações judiciais. A partir das entrevistas com os agentes verificou-se que o problema foi concentrado no Estado de Goiás, fato comprovado pelo volume de disputas judiciais sobre o tema naquele Estado.

O Brasil adota o sistema jurídico codificado tendo recebido influência, entre outros, do código francês. Alguns pilares desse código se sustentam no poder absoluto da propriedade e na intangibilidade dos contratos. Dentro dessa perspectiva desenvolveu-se a expressão pacta sunt servanda, ${ }^{2}$ que preconiza a imutabilidade da intenção existente no momento do pacto entre as partes contratantes, que passa a servir de orientação da ação do judiciário no caso de disputas. Segundo essa interpretação, não se admite o descumprimento de pactos assumidos em situação de liberdade e entre iguais (Santos, 2004). Por outro lado, o Código Civil brasileiro reformado em 2002 introduziu em seu art. 421 o balizamento com forte teor social, 
concretizado pelo conceito de "função social do contrato". A liberdade de contratar passa a ser entendida dentro dos limites, nem sempre bem delineados, da função social do contrato. Este artigo discute possíveis impactos advindos das interpretações dos juízes que lançam mão ou acatam argumentos baseados no conceito jurídico de função social do contrato.

A maior parte das decisões judiciais de segunda instância acatou o argumento do papel social dos contratos, dando ganho de causa aos agricultores que romperam os contratos. Tal fato gerou efeitos de segunda ordem na forma do aumento da instabilidade no mercado. As entrevistas realizadas com as empresas compradoras indicaram que as indústrias/tradings efetuaram menos contratos de compra antecipada de soja verde nos anos seguintes e algumas extinguiram a modalidade que não envolve financiamento. Esse fato pode ter sido causado pela queda dos preços da soja, o que teria possibilitado alternativas para a aquisição por parte das empresas, ou como medida de precaução decorrente das decisões dos juízes. A última hipótese foi o objeto de estudo de nossa pesquisa.

Neste artigo procuramos identificar como o rompimento dos contratos de compra e venda antecipada de soja e as respectivas decisões judiciais impactaram a redefinição das estratégias dos agentes desse sistema agroindustrial. Para isso, foram realizadas entrevistas com representantes desse sistema agroindustrial, bem como revisão bibliográfica, pesquisa de campo estruturada e coleta de dados sobre decisões judiciais existentes. O referencial teórico utilizado toma como fundamento a Economia de Custos de Transação, de modo especial a análise do ambiente institucional. Diferentemente da análise neoclássica, esse instrumental considera, entre outros pontos, que existem custos de transação e que as instituições podem ser ineficientes, com implicações para agentes econômicos (North, 1990).

O estudo está estruturado em seis seções. Na segunda o sistema agroindustrial da soja é descrito, servindo de referência para a compreensão do cenário onde o fenômeno estudado ocorre. Na seção III o método adotado é apresentado, com ênfase no uso da análise positiva dos dados obtidos junto ao judiciário. Na IV detalhamos os mecanismos encontrados de prevenção e solução de disputas, contempla a pesquisa empírica sobre as decisões judiciais do Tribunal de Justiça do Estado de Goiás que versam sobre o conflito em questão. Na sequência (seção V) tratamos da instabilidade gerada no ambiente econômico, constatada por meio de entrevistas com produtores rurais e representantes de empresas processadoras. Ao final, têmse as conclusões.

\section{O SISTEMA AGROINDUSTRIAL DA SOJA E OS CONTRATOS DE SOJA VERDE}

O Brasil se consolidou como um dos maiores produtores de grãos do mundo. Em face das elevadas taxas de juros que caracterizam a economia brasileira, e pelo fato 
de o financiamento com recursos a taxas preferenciais ser limitado, surgiram arranjos alternativos para a obtenção de crédito, como, por exemplo, os contratos de venda antecipada de soja, chamados de contratos de soja verde, estudados por Almeida (2008). A partir de 1990 tais contratos propiciaram a comercialização de insumos e o fornecimento de crédito para custeio da produção em troca dos grãos de soja a serem colhidos na safra seguinte. Posteriormente, intensificou-se a modalidade sem a antecipação de recursos, com o objetivo de estabelecer o preço de venda e reduzir os impactos da oscilação do preço na época da safra.

Quando há adiantamento de recursos, ou seja, quando uma das partes adianta o cumprimento da obrigação contratual, pagando antecipadamente, são exigidas garantias reais, como, por exemplo, a propriedade rural. Em geral, esses contratos também são garantidos por emissão de Cédula de Produto Rural (CPR). Na safra 2003/2004 um número expressivo de produtores de soja venderam seu produto antecipadamente, por meio de contrato, em média a US\$ 10 o saco de 60 quilos, porém, no momento da entrega do produto as cotações chegaram a US\$ 17 e R\$ 54,00. Essa oscilação gerou conflitos entre os agricultores e as processadoras ou tradings, uma vez que muitos agricultores alegaram se sentir lesados por não terem acesso aos preços praticados no mercado à época da colheita.

Os atores apontam distintas interpretações para o conflito, porém, qualquer que seja a interpretação configura-se um problema pós-contratual que gerou abalos na coordenação do sistema agroindustrial da soja, evidenciado pela ocorrência de quebras contratuais por parte de agricultores que preferiram destinar o produto ao mercado. A decisão acarretou processos judiciais e penalidades privadas na forma da redução no volume de contratos praticados na safra seguinte.

O sistema agroindustrial (SAG) de determinado produto é definido como o conjunto dos segmentos envolvidos na produção, transformação e distribuição daquele produto (Zylbersztajn, 1995). O conceito extrapola os agentes envolvidos com produção e transformação, envolvendo também as organizações e as instituições que lhes dão suporte. Mais amplo do que o conceito de cadeias produtivas, a análise sistêmica focaliza a coordenação do sistema e as relações tecnológicas e econômicas que se estabelecem entre os segmentos do sistema (Zylbersztajn; Farina, 1999). O SAG da soja envolve a indústria de insumos agrícolas, os produtores rurais, os comerciantes de soja em contato direto com produtores, a indústria esmagadora, os distribuidores e consumidores finais. As transações são influenciadas pelo ambiente institucional, que envolve o sistema jurídico e judicial em temas como direitos de propriedade intelectual, regulação ambiental, entre outros.

\section{I Ambiente institucional COMO RedUTOR DE INCERTEZAS}

Os referenciais teóricos utilizados nesta análise são enraizados na Nova Economia Institucional e da Análise Econômica do Direito. O artigo focaliza o papel do ambiente 
institucional como redutor de incertezas, especialmente no que se tange à influência do judiciário nas relações econômicas.

Enquanto a teoria econômica tradicional estuda os mercados e considera a empresa como uma função de produção, minimizadora de custos indiferente à sua estrutura interna e às condições do ambiente, exceto aos preços, a Nova Economia Institucional (NEI) aborda a estrutura interna da empresa, suas relações verticais e horizontais (Zylbersztajn, 1995).

A Análise Econômica do Direito e das Organizações é um campo teórico que tem se desenvolvido em ritmo acelerado nos últimos anos a partir de diversas vertentes. Neste artigo será tratada sob a luz da Nova Economia Institucional.

Partindo da base teórica fornecida pelos trabalhos de Ronald Coase, Douglas North e Oliver Williamson, Zylbersztajn e Sztajn (2005) afirmam que a Análise Econômica do Direito e das Organizações com base no instrumental teórico da Nova Economia Institucional adota o conceito de racionalidade limitada, flexibiliza a hipótese clássica de que as instituições evoluem necessariamente de forma eficiente, e explica por que surgem direitos de propriedade e formas de alocação de recursos econômicos ineficientes.

Em 1937 Coase, em seu artigo "The nature of the firm", abriu expectativas ao estudo da indústria com foco nos aspectos organizacionais internos e de relacionamento com clientes e fornecedores. Em outro artigo de 1960 ("The problem of social cost”) o autor lembra que as instituições não seriam necessárias se não existisse assimetria informacional e se os custos de transação fossem iguais a zero. Como essa situação é inexistente no mundo real, as instituições possuem um papel crucial na alocação dos recursos.

O ambiente institucional é formado por entidades que determinam as normas que serão seguidas e o sistema de controle. A forma pela qual está estruturado o ambiente institucional pode interferir diretamente nos custos de produção e de transação. North (1990) considera as instituições como as "regras do jogo" da sociedade, pois são elas que estruturam os incentivos para as interações humanas, tanto sociais, como políticas e econômicas.

Barzel (1997) define custo de transação como o custo associado à transferência, captura e proteção dos direitos de propriedade, logo o ambiente institucional afeta a eficiência na transferência do direito de propriedade e os custos de transação. Quando existem falhas institucionais que podem definir o direito de propriedade de forma subótima, os agentes econômicos se rearranjam e definem outra forma de garantir esse direito.

No caso da compra antecipada de soja verde, com a ausência de garantias do Estado no cumprimento do direito de propriedade legal, espera-se a sua substituição por sanções econômicas privadas.

Klein (1992) privilegia os mecanismos privados de sustentação das transações. Ele argumenta que existem custos e benefícios em decorrência das quebras contratuais. 
No âmbito do conceito de autorregulação (self-enforcing range), cada agente avaliará se os ganhos serão maiores do que o custo das sanções jurídicas (de natureza pública) e econômicas (de natureza privada). As sanções jurídicas são estipuladas nos contratos na forma de multas e são passíveis de coerção judicial. As sanções econômicas não são explicitadas no contrato, mas possuem importância, sobretudo nas próximas relações, como ocorre com a reputação do indivíduo.

Em relação ao caso dos produtores de soja que quebraram seus contratos, a elevação do preço gerou incentivos para a quebra contratual, e em consequência, o ajuizamento de ações judiciais. ${ }^{3}$ Em decorrência os agricultores tiveram efeitos em sua reputação, que afetaram as transações seguintes com potenciais prejuízos econômicos.

De acordo com Arruñada e Andonova (2005) "O funcionamento adequado de uma economia de mercado requer a efetiva tutela da liberdade de contratar". A criação de riqueza depende das trocas, essa transação requer definição dos seus termos e controle de incertezas quanto ao cumprimento desses termos, ou seja, são necessários normas e tribunais. O papel das cortes é preencher lacunas existentes nos contratos que por pressuposto são incompletos e, com isso, reduzir custos de transação para os agentes.

Todos os tipos de elaboração de regras, contudo, estão sujeitos a ineficiências, devido à existência de autointeresse, informação incompleta e racionalidade limitada dos agentes. Tanto os legisladores como os juízes podem falhar devido ao interesse privado ou, mesmo na sua ausência, podem falhar ao identificar quais regras são mais apropriadas para cada caso (Arruñada; Andonova, 2004).

Quaisquer que sejam as causas e justificativas para as quebras contratuais, as decisões dos tribunais sobre a quebra de contratos geram impactos nas estratégias das organizações. O ambiente institucional é capaz de afetar os custos de transação das organizações, em especial na sua capacidade de garantir os contratos formais ou informais.

\section{I.2 NOVA ORIENTAÇÃO DA TEORIA CONTRATUAL}

Segundo Sztajn e Gorga (2005), o direito brasileiro faz parte da chamada família romano-germânica, cuja característica típica é a representação da lei pelo direito codificado, um conjunto sistemático de normas jurídicas que aparecem em códigos de direito privado (civil e comercial) ou público, com o objetivo de disciplinar as relações, descrever condutas, efeitos de manifestações da vontade e punições.

De acordo com Santos (2004), o Código Civil francês foi incorporado por grande parte dos países da família romano-germânica ou direito codificado. Alguns pilares desse código se sustentavam no conceito pétreo de propriedade e na intangibilidade dos contratos. Ele foi desenvolvido em uma época marcada por características sociais do individualismo, da igualdade e da liberdade. O princípio do pacta sunt servanda teve prioridade no Código Civil francês do século XIX, prevendo 
que a intenção de um acordo deveria ser mantida. A interpretação econômica desse preceito é permitir controlar as instabilidades, reduzindo custos transacionais e, em consequência, aumentando o potencial de cooperação na sociedade. O Código Civil brasileiro, em seu art. 421, afirma que "a liberdade de contratar será exercida em razão e nos limites da função social do contrato”. Esse artigo do Código Civil tem sido interpretado de diversas formas, uma delas é que ele fragiliza os contratos; Reale (2004), no entanto, afirma que a nova Lei Civil não conflita com o princípio de que o pactuado deve ser cumprido. Segundo ele, o imperativo da "função social do contrato" estatui que ele não pode ser transformado em um instrumento para atividades abusivas, causando dano à parte contrária ou a terceiros.

Timm (2006) analisa a doutrina e identifica que a função social do contrato é vista por muitos juristas como uma limitação ao princípio da liberdade contratual e ainda comenta que "com base na função social do contrato alguns juízes tem revisado o contrato com o argumento político de proteger o fraco contra o forte, a coletividade frente à individualidade".

De acordo com Delgado (2006) o dispositivo 421 que trata da função social do contrato alarga ainda mais a capacidade do juiz de proteger o mais fraco que possa sofrer pressão econômica ou efeito de cláusulas abusivas. Ou seja, aumenta o poder do juiz. Delgado comenta a teoria da imprevisão (art. 478 no novo Código Civil) que se apresenta com o intuito de abrandar a aplicação do princípio pacta sunt servanda, quando ocorre uma alteração brusca das situações existentes no momento da contratação. Esse princípio foi elaborado e acolhido na França durante a $1^{\mathrm{a}}$ Guerra Mundial.

Percebe-se, portanto, que há casos em que a intervenção faz-se necessária, porém, a revisão ou anulação de contratos firmados pode aumentar a incerteza e, consequentemente, os custos de transação para todos os agentes.

$\mathrm{Na}$ literatura de análise econômica do direito, o papel do contrato é visto como elemento gerador de incentivos para a alocação de esforços conjuntos de produção. O contrato é, por natureza, incompleto e gera espaço para interpretações ex-post. O papel das cortes é alocar direitos de propriedade no caso de quebras contratuais. Diferentes vertentes da literatura consideram as cortes como instituições eficientes, ou como instituições sujeitas a captura e limitações cognitivas similares às dos agentes contratantes.

\section{PROCEDIMENTOS METODOLÓGICOS}

$\mathrm{Na}$ primeira fase do trabalho, foram realizadas entrevistas qualitativas com produtores, empresários, advogados e representantes de entidades de classe. Essas pesquisas tiveram como objetivo caracterizar os produtores e as empresas, buscando contextualizar e aprofundar o estudo do setor e, principalmente, identificar os principais problemas percebidos para a realização dos contratos. Após dois anos, foram realizadas novas 
entrevistas com empresários representantes de indústrias com o objetivo de coletar evidências da instabilidade causada no ambiente de negócios. Essas entrevistas foram usadas na composição da última seção deste artigo.

A partir da pesquisa qualitativa, foi elaborado um roteiro para a coleta de dados com produtores rurais. Foram aplicados 70 questionários aos produtores de soja que realizaram pelo menos uma venda antecipada de soja nas última três safras, a saber, 2002/2003, 2003/2004 e 2004/2005. As informações por unidade da Federação foram obtidas da seguinte forma: 68\% foram provenientes do Estado de Goiás; 15\%, de Mato Grosso; 13\%, do Paraná; e 4\%, provenientes do Rio Grande do Sul, Mato Grosso do Sul, Bahia e Maranhão. O período de aplicação foi de setembro a novembro de $2005 .^{4}$

A pesquisa sobre decisões judiciais no nível de segunda instância foi realizada pela Internet, por Jurisprudência. Inicialmente, foi realizada nos sites dos Tribunais de Justiça dos Estados de Goiás, Mato Grosso, Mato Grosso do Sul e Paraná. Foram consideradas apenas as apelações cíveis sobre os casos de rescisão de contrato de compra e venda de soja e ações declaratórias de nulidade de contratos. O Estado de Goiás foi o foco do estudo por apresentar um número de casos que permitiu a análise estatística, além disso, as entrevistas qualitativas indicaram um número maior de conflitos. O tribunal de justiça de Goiás foi o escolhido para acompanhamento do andamento dos processos sobre o conflito. A última busca por decisões ocorreu em setembro de 2007, quando foram tabuladas 161 decisões, sendo a primeira de novembro de 2003 e a última de agosto de 2007.

Em resumo, foram realizadas pesquisas de campo com agentes do agronegócio (qualitativa), com produtores rurais (quantitativa) e sobre decisões judiciais (quantitativa).

\section{I Características da Amostra das decisões JUdiciais}

Estão disponíveis na internet as ementas dos acórdãos das decisões e, em parte dos casos, o chamado "Inteiro Teor do Acórdão" que contém um breve relatório sobre o caso e a argumentação que justifica o voto prevalecente do relator ou redator.

Das 161 apelações cíveis encontradas, 78 continham o inteiro teor do acórdão digitalizado; 64 foram copiadas diretamente no Tribunal de Justiça em Goiânia; e em 19 casos os acórdãos não estavam disponíveis em nenhuma das formas, pois ainda estavam em processo de digitalização.

\subsection{Forma de ANÁLISE doS Resultados}

Os dados foram tratados com as seguintes ferramentas estatísticas:

- Estatística descritiva: apresentação de medidas de tendência central e da distribuição das frequências em gráficos ou tabelas. 
- Estatística inferencial: análise de regressão utilizando modelo de variáveis dependentes limitadas, tendo como variáveis dependentes as decisões em vários níveis - decisão de primeiro grau; decisão de segundo grau; decisão do juiz ou desembargador que compôs a decisão da apelação.

A decisão judicial é tomada como decisão binária, ou seja, pode assumir apenas dois valores a partir do julgado no tribunal, quais sejam: favorável à manutenção do contrato ou à sua anulação. Sendo assim, a decisão judicial é considerada como variável dependente limitada binária (VDL) com os seguintes valores:

$$
y=\left\{\begin{array}{l}
1=\text { favorável à manutenção do contrato } \\
0=\text { favorável à anulação do contrato }
\end{array}\right\}
$$

Em nossa pesquisa foi usado o modelo probit com o objetivo de identificar como as variáveis explicativas afetam a probabilidade de o contrato ser mantido, ceteris paribus. Segundo a equação 1:

$$
P(\text { decisão }=1 \mid x)=\Phi\left(\beta_{0}+\beta_{1} x_{1}+\beta_{2} x_{2}+\ldots+\beta_{n} x_{n}\right)
$$

Os sinais dos coeficientes indicam os efeitos parciais de cada variável sobre a probabilidade de resposta e a significância estatística de cada variável dirá se é possível rejeitar $H_{0}: \beta_{J}=0$ considerado um nível de significância predefinido (Wooldridge, 2006 pag. 523 e 524).

\section{MECANISMOS DE PREVENÇAO E SOLUÇÃO DE DISPUTAS}

Durante o desenvolvimento da pesquisa foram identificados mecanismos privados de prevenção de conflitos e mecanismos públicos de solução de disputas, que são as decisões judiciais. Os mecanismos privados podem ser informais ou formais (podem estar formalmente descritos no contrato ou não).

Agricultores que optaram pelo cumprimento dos contratos comentaram que o fizeram para garantir a sua reputação. No mercado de soja, os contratos são renovados anualmente levando o produtor a temer por retaliação nas negociações seguintes, ou seja, teme por sanções econômicas.

Nos casos em que houve antecipação de recurso financeiro, de acordo com os agentes entrevistados, alguns advogados recomendaram aos produtores a manutenção do contrato, pois acreditavam que o judiciário decidiria a favor das empresas. Essa situação demonstra que, quando o direito de propriedade é adequadamente definido, há uma sinalização da justiça que implica a redução da demanda por ações judiciais. 
O mecanismo de solução formal público para o conflito é substanciado na decisão do judiciário. Os vários conflitos resultaram em ações judiciais impetradas por produtores e indústrias/tradings para definição do direito de propriedade. De acordo com as entrevistas e a pesquisa sobre as ações, ao final de 2005 havia mais de 300 processos no judiciário sobre esse tema.

\section{I AnÁlises estatísticas descritivas}

As decisões analisadas são apelações cíveis, também chamadas de decisões de segundo grau. O Estado de Goiás possui 119 comarcas, destas, 14 foram incluídas em nossa análise, pois elas enviaram os processos para o Tribunal de Justiça em Goiás acerca dos contratos de soja verde no período observado.

Após a decisão do juiz de direito na comarca a parte que se julgar prejudicada pode apelar para o Tribunal de Justiça, nesse caso o processo passará a ser uma Apelação Cível. ${ }^{5}$ O Tribunal de Justiça de Goiás (TJGO) é sediado na capital do Estado e é composto de 22 desembargadores.

Os processos relacionados aos contratos de compra e venda de soja verde vão para as chamadas "câmaras cíveis isoladas", em número de 4, que decidem de forma simultânea e independente. O processo, uma vez recebido pelo TJGO, é sorteado eletronicamente para uma dessas câmaras. O sorteio é realizado com o propósito de equilibrar o número de processos entre as câmaras e para evitar que o apelante escolha a câmara em que a apelação será julgada. A tabela 1 mostra como foi a divisão das ações analisadas entre as Câmaras e a porcentagem de decisões favoráveis aos produtores e às indústrias em cada uma delas.

Tabela i - Decisões por Câmara Cível do Tribunal de Justiça de Goiás

\begin{tabular}{|c|c|c|c|c|}
\hline & \multirow[b]{2}{*}{ CÂMARA CÍVEL } & \multicolumn{2}{|l|}{ DECISÕES } & \multirow[b]{2}{*}{ TOTAL } \\
\hline & & PRODUTOR & INDÚSTRIA & \\
\hline \multirow[t]{2}{*}{1} & QUANTIDADE & 36 & 2 & 38 \\
\hline & $\%$ & $94,7 \%$ & $5,3 \%$ & $100 \%$ \\
\hline \multirow[t]{2}{*}{2} & QUANTIDADE & 1 & 32 & 33 \\
\hline & $\%$ & $3,0 \%$ & $97,0 \%$ & $100 \%$ \\
\hline \multirow[t]{2}{*}{3} & QUANTIDADE & 40 & 8 & 48 \\
\hline & $\%$ & $83,3 \%$ & $16,7 \%$ & $100 \%$ \\
\hline \multirow[t]{2}{*}{4} & QUANTIDADE & 7 & 35 & 42 \\
\hline & $\%$ & $16,7 \%$ & $83,3 \%$ & $100 \%$ \\
\hline \multirow[t]{2}{*}{ TOTAL } & QUANTIDADE & 84 & 77 & 161 \\
\hline & $\%$ & $52,2 \%$ & $47,8 \%$ & $100 \%$ \\
\hline
\end{tabular}


Observa-se que as decisões dos juízes e dos desembargadores sobre esse conflito não foram convergentes. Com o intuito de entender a diversidade de opiniões sobre um conflito semelhante, fizemos uma análise dos argumentos usados nas decisões das apelações.

Em uma apelação o desembargador ou juiz substituto responsável apresentou os argumentos balizadores do seu voto. Para que fosse possível a sua quantificação foi necessário uma simplificação: para cada decisão procedeu-se à análise de conteúdo e foi escolhido apenas um argumento, o que melhor a representasse.

Em decisões favoráveis aos produtores os argumentos escolhidos foram: (1) nova orientação da teoria contratual; (2) ilegitimidade do título Cédula de Produto Rural; (3) teoria da imprevisão; e (4) Código de Defesa do Consumidor.

Em decisões favoráveis às indústrias/tradings os argumentos principais foram: (1) não aplicabilidade da teoria da imprevisão; (2) legitimidade do título Cédula de Produto Rural; e (3 ) não aplicabilidade do Código de Defesa do Consumidor.

$\mathrm{Na}$ amostra analisada 75\% das decisões favoráveis aos produtores rurais estavam relacionadas à "nova orientação da teoria contratual”, que compreende os princípios da função social do contrato, de boa-fé e do equilíbrio econômico, arts. 421 e 422 do Novo Código Civil.

Nas decisões favoráveis à indústria, o argumento mais frequente foi o da não aplicabilidade da teoria da imprevisão. Em 92\% dos casos analisados, os juízes consideraram que a alteração ocorrida nos preços não podia ser interpretada como imprevista pelas partes e não justificava a anulação do contrato.

Após o sorteio da câmara cível é definida uma turma julgadora para cada processo, composta de 3 três juízes, sendo um deles o relator.

Ao relator, desembargador ou juiz substituto, cabe analisar o caso e dar seu voto com os argumentos que julgar adequados para cada caso. Na sessão de julgamento, o relator, após breve apresentação do caso, explica para os outros dois membros da respectiva turma julgadora os argumentos balizadores do seu voto. Os outros membros podem seguir ou não o voto do relator. Caso os outros dois votem de forma contrária, um deles será designado como redator do caso devendo preparar um novo parecer com voto e a justificativa que constará na ementa e no "inteiro teor do acórdão". 6

Conforme esperado, foi constatado que a maior parte dos juízes (64\%) vota próprodutor ou pró-indústria em cem por cento dos casos. A constatação da disparidade sistêmica do voto foi a motivação para a busca por características explicativas do comportamento dos juízes, o que será tratado em Análise estatística e econométrica.

\section{I . i Decisões do STJ}

A primeira das decisões acerca dos casos de compra e venda de safra futura de soja no Superior Tribunal de Justiça foi do Ministro Ari Pargendler (DJ: 20/02/2006 REsp 722.130/GO) e, desde então, a jurisprudência é indicativa da manutenção 
desses contratos, uma vez que a alteração no valor do preço não foi considerada como fato imprevisível.

Foram encontrados 20 recursos especiais, com 8 decisões. O pequeno número de recursos sugere que a jurisprudência que está sendo formada fortalece a tese da manutenção dos contratos, explicando a mudança da decisão de alguns juízes após fevereiro de 2006, como será mostrado na próxima seção.

\section{I. 2 Análise estatística e eCONOMÉtrica}

Como já foi comentado, foram analisadas 161 decisões de Apelações Cíveis. Em 142 desses processos foi possível identificar o voto dos 3 juízes, então, parte da análise contém 426 observações. Logo, as amostras serão identificadas como A e B para o tratamento econométrico, de acordo com sua composição de variáveis.

A amostra A contém 161 observações tendo sido estimadas 4 regressões com objetivos distintos. As duas primeiras (A1 e A2) pretendem testar se a probabilidade de o contrato ser mantido nas duas instâncias e entre as câmaras cíveis é semelhante. A hipótese sugerida pela teoria é que se o judiciário é imparcial não haverá significância estatística entre as variáveis.

A primeira regressão, A1, testa se existe diferença significante entre a probabilidade de o contrato ser mantido na primeira e na segunda instância. A variável dependente contém as decisões de primeira e segunda instância e a variável explicativa foi uma variável dummy para decisão 2 (decisão $2=1$ e decisão $1=0$ ). Assim, o modelo foi:

\section{$P($ decisões 1 e $2=1 \mid x)=\Phi\left(\beta_{0}+\beta_{1} \operatorname{dec} 2\right)$}

O segundo teste (A2) busca identificar a probabilidade de manutenção do contrato entre as diferentes Câmaras Cíveis. Como não é possível testar as quatro juntas, pois uma variável seria suprimida devido à colinearidade, foram realizadas duas regressões probit (A2.1 e A2.2) com a variável dependente: Decisão da Apelação Cível. São elas:

\section{Teste A2.1}

$P(\operatorname{dec} 2=1 \mid x)=\Phi\left(\beta_{0}+\beta_{1} \operatorname{Cam} 1+\beta_{2} \operatorname{Cam} 2+\beta_{3}\right.$ Cam3 $)$

Variáveis independentes: (1) Câmara Cível 1 (dummy: Câmara Cível $=1$; outras câmaras $=$ 0); (2) Câmara Cível 2 ((dummy: Câmara Cível $=2$; outras câmaras $=0)$; (3) Câmara Cível 3 ( (dummy: Câmara Cível $=3$; outras câmaras $=0)$.

\section{Teste A2.2}

\section{$P(\operatorname{dec} 2=1 \mid \mathrm{x})=\Phi\left(\beta_{0}+\beta_{1} \operatorname{Cam} 2+\beta_{2} \operatorname{Cam} 3+\beta_{3}\right.$ Cam4 $)$}

Variáveis independentes: Câmara Cível 2 ((dummy: Câmara Cível $=2$; outras câmaras $=0)$; (2) Câmara Cível 3 ((dummy: Câmara Cível = 3; outras câmaras $=0)$; (3) Câmara Cível 4 (dummy: Câmara Cível $=4$; outras câmaras $=0$ ). 
Como no primeiro teste, a hipótese na regressão A2 é que a probabilidade de a decisão ser favorável à manutenção do contrato não está relacionada com a Câmara Cível de origem do processo. A tabela 2 apresenta os resultados consolidados.

\section{TABELA 2 - COEFICIENTES DO MODELO DE REGRESSÃo PROBIT DA VARIÁVEL “DECISÃO FAVORÁVEL À MANUTENÇÃO DO CONTRATO" EM FUNÇÃO DA INSTÂNCIA DA DECISÃo E DA CÂMARA CÍVEL}

\begin{tabular}{l|l|l|l} 
REGRESSÕES & \multicolumn{1}{l}{ A1 } & A2.1 & \multicolumn{2}{l}{ A2.2 } \\
\hline VARIÁVEIS & & & \\
\hline DECISÃO 2 & $-0,3793068^{* * *}$ & & $-2,587278^{* * *}$ \\
\hline CÂMARA 1 & & $3,496215^{* * *}$ & 0,908937 \\
\hline CÂMARA 2 & & 0,6524347 & $-1,934843^{* * *}$ \\
\hline CÂMARA 3 & & $2,587278^{* * *}$ & \\
\hline CÂMARA 4 & & $-1,619856$ & 0,9674216 \\
\hline CONSTANTE & 0,3247879 & $* * *$ significa & \\
\hline
\end{tabular}

Erro padrão robusto; ${ }^{* * *}$ significante a $1 \% ;{ }^{* *}$ significante a $5 \% ;{ }^{*}$ significante a $10 \%$.

No teste A1 a variável Decisão 2 apresentou significância estatística. Na sequência foi identificado que quando o valor da variável é 1, ou seja, quando a decisão é de segunda instância, a probabilidade de o contrato ser mantido é de $47,82 \%$, e se o valor for 0 , o que caracteriza a decisão de primeira instância, esse percentual é de $62,73 \%$, ceteris paribus. $^{7}$

Na tabela 2, observa-se também que as variáveis Câmara 1 e Câmara 3 foram significantes no teste A2.1, enquanto, no teste A2.2 se têm as Câmeras 2 e 4 como significantes. Analisando a probabilidade de o contrato ser mantido para os diferentes valores tem-se que: quando a decisão foi proveniente da Câmara 1, a probabilidade de o contrato ser mantido foi de 2,21\%; já na Câmara 3 esse valor é de $8,2 \%$. Enquanto na Câmara 2 a probabilidade de o contrato ser mantido foi de $99,7 \%$, na Câmara 4 foi de 96,98\%, ceteris paribus. Esse resultado revela a diversidade de comportamento entre as decisões de primeira e segunda instâncias e entre as turmas julgadoras das Câmeras Cíveis na amostra estudada.

A partir desses dados, o objetivo foi identificar se as variáveis associadas ao estado de origem da empresa e o fato de o produtor ter recebido adiantamento de recursos financeiros ou na forma de insumos tem algum efeito preditivo sobre a decisão de primeiro grau.

O modelo adotado na regressão A3 é apresentado na equação 4: 


\section{$P($ decisão1 $=1 \mid x)=\Phi\left(\beta_{0}+\beta_{1}\right.$ adiant $+\beta_{2}$ empgoiana $)$}

A hipótese a ser testada nessa regressão é que o adiantamento de recursos caracteriza a transferência de direito de propriedade, logo, espera-se que a variável tenha sinal positivo e significância estatística. Por outro lado, não se espera que o fato de a empresa ter sede em Goiás tenha influência significante na decisão do juiz.

A Regressão A4 tem como variável dependente a decisão da corte de apelação (dummy: manutenção do contrato $=1$; não manutenção $=0$ ). São variáveis explicativas: (1) Estado de origem da empresa (dummy identificadora se o estado de origem é Goiás: $\operatorname{sim}=1$; não $=0)$; (2) adiantamento de recursos financeiros (dummy: presença $=1$; ausência $=0)$; (3) ano em que a decisão foi tomada $(2003,2004,2005$, 2006 ou 2007); (3) unanimidade da decisão (dummy sim $=1$ ou não $=0$ ); (4) sustentação oral do advogado do produtor rural (dummy sim $=1$ ou não $=0)$; (5) sustentação oral do advogado da indústria (dummy sim $=1$ ou não $=0)$.

O modelo é apresentado na equação 5.

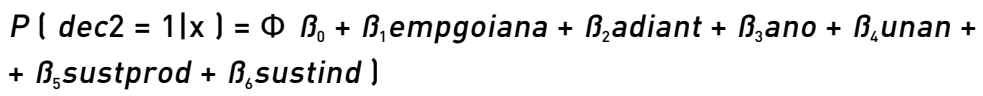

Conforme comentado anteriormente, a amostra B contém 426 observações, pois contempla o voto e argumento de cada um dos 3 juízes que compõem a turma julgadora, inclusive os que foram vencidos na votação. Com essa amostra pretendese testar se as variáveis independentes identificadas possuem efeito preditivo no voto individual do juiz e, caso apresentem significância, será estimado quanto influem na probabilidade do contrato ser mantido, ceteris paribus. O sinal de 1 indicará se a relação com a variável dependente é positiva ou negativa.

O modelo é composto pela variável dependente: voto individual do juiz de segundo grau; o sucesso é a manutenção do contrato.

São variáveis dummies independentes: (1) título (desembargador $=1$ ou doutor $=0)$; (2) gênero (masculino $=1$ ou feminino $=0$ ); (3) unanimidade da decisão ( $\operatorname{sim}$ $=1$ ou não $=0)$; (4) sustentação oral do advogado do produtor rural (presença $=$ 1 ou ausência $=0$ ); (5) sustentação oral do advogado da indústria (presença $=1 \mathrm{ou}$ ausência $=0)$; (6) antecipação de recursos financeiros ou insumos por parte da indústria (presença $=1$ ou ausência $=0)$; $(7)$ decisões após fev. $/ 2006\left(1^{\text {a }}\right.$ decisão do STJ $)(\operatorname{sim}=1$ ou não $=0)$.

Assim, o modelo estimado é apresentado na equação 6.

$$
P(\text { voto }=1 \mid x)=\Phi\left(\begin{array}{l}
\beta_{0}+\beta_{1} \text { titulo }+\beta_{2} \text { genero }+\beta_{3} \text { adiant }+\beta_{4} \text { unan } \\
\beta_{5} \text { sustoralprod }+\beta_{6} \text { sustoralempresa }+\beta_{7} \text { st } j
\end{array}\right)
$$


Os coeficientes das regressões, bem como os sinais que eram esperados, podem ser visualizados na tabela 3 .

\section{TABELA 3 - COEFICIENTES E SINAIS ESPERADOS DAS REGRESSÕES PROBIT REALIZADAS}

\begin{tabular}{r|l|l|l|l|l|l}
\multicolumn{1}{r}{ SE } & A3 & \multicolumn{1}{c}{ SE } & A4 & \multicolumn{1}{c}{ SE } & B \\
\hline ADIANTAMENTO DE RECURSOS & + & 0058155 & + & $0,9890149 * *$ & + & $1,495814^{* * *}$ \\
\hline EMPRESA GOIANA & & $0783418^{* * *}$ & & 0,2326133 & & \\
\hline ANO & & & & $0,2901976^{* *}$ & & \\
\hline SUSTENTAÇÃO ORAL DO PRODUTOR & & & & $-0,0965621$ & & $-0,3852985^{* *}$ \\
\hline SUSTENTAÇÃO ORAL DA INDÚSTRIA & & & - & $-0,2564388$ & - & $-0,1934741$ \\
\hline TITULO & & & + & 0,3342063 & + & $0,3839906^{* *}$ \\
\hline GÊNERO & & & & & & $0,5032658^{* *}$ \\
\hline STJ & & & & & & 0.3157261 \\
\hline CONSTANTE & & 0,06678 & & 5820,448 & & $-0,7835735$ \\
\hline
\end{tabular}

$\mathrm{SE}=$ Sinal esperado; ${ }^{* * *}$ significante a $1 \% ;{ }^{* *}$ significante a $5 \% ;{ }^{*}$ significante a $10 \%$.

Na regressão A3 foi constatada a significância estatística na variável "Empresa goiana" sobre a decisão de primeiro grau, contrariando a hipótese de que o Estado de origem não influenciaria na decisão do juiz. O teste realizado para captar seu efeito na probabilidade da decisão do juiz ser favorável à manutenção do contrato indica que, quando seu valor é 1 , ou seja, quando a empresa é goiana, a probabilidade é de $76,4 \%$, e se o valor é zero essa probabilidade é de 47,4\%, ceteris paribus.

Em 53\% das observações da amostra, as indústrias possuem sede em Goiás. É o caso das empresas: Caramuru, Selecta e Cooperativa Mista dos Produtores Rurais do Sudoeste Goiano (Comigo).

Na regressão A4 as variáveis que apresentaram significância foram: ano e adiantamento de recursos. O sinal positivo da variável ano indica que a probabilidade da decisão de segunda instância ser favorável à manutenção do contrato aumentou a cada ano, o que foi comprovado posteriormente, como mostra a tabela 4. 
Tabela 4 - Probabilidade de A Decisão de Segunda instância SER FAVORÁVEL À MANUTENÇÃO DE CONTRATOS DE 2003, 2004, 2005, 2006 OU 2007, CETERIS PARIBUS

\begin{tabular}{rlllll} 
ANO & $\mathbf{2 0 0 3}$ & $\mathbf{2 0 0 4}$ & $\mathbf{2 0 0 5}$ & $\mathbf{2 0 0 6}$ & $\mathbf{2 0 0 7}$ \\
\hline DECISÃO $=1$ & $25,51 \%$ & $35,63 \%$ & $46,88 \%$ & $58,40 \%$ & $69,22 \%$ \\
\hline
\end{tabular}

Conforme esperado, a variável adiantamento de recursos influi positivamente na probabilidade de a decisão ser favorável à manutenção do contrato. Quando seu valor é 1, ou seja, quando o produtor recebeu algum tipo de adiantamento, a probabilidade de a decisão ser favorável à indústria é de $81 \%$ contra $46,8 \%$ nos casos onde não houve adiantamento, ceteris paribus.

A regressão B tem como variável dependente a decisão individual do juiz, que pode ser desembargador ou juiz substituto. Nessa regressão foram consideradas significantes as variáveis: título do juiz; unanimidade da decisão; sustentação oral da empresa; adiantamento de recursos e decisão do STJ.

O sinal indica que apenas a unanimidade possui relação negativa com o voto do juiz pela manutenção do contrato. Os valores na tabela 5 indicam que, ceteris paribus, nos casos em que houve divergência da turma julgadora a probabilidade do resultado ser favorável à manutenção do contrato foi maior do que quando houve unanimidade. Os resultados indicam que a unanimidade tende a favorecer o hipossuficiente.

Tabela 5 - Probabilidade de O Voto individual do Desembargador ou JUIZ SUBSTITUTO SER FAVORÁVEL À MANUTENÇÃO DO CONTRATO QUANDO ÀS VARIÁVEIS: TÍTULO; UNANIMIDADE; SUSTENTAÇÃO ORAL DO ADVOGADO DA INDÚSTRIA; ADIANTAMENTO DE RECURSOS FINANCEIROS; E DECISÃO APÓS A PRIMEIRA SENTENÇA DO STJ TIVERAM COMO VALOR ZERO E UM, CETERIS PARIBUS

\begin{tabular}{|c|c|c|}
\hline VARIÁVEL SIGNIFICANTE & VALOR = 1 & VALOR $=0$ \\
\hline $\begin{array}{l}\text { TíTULO } \\
(1=\text { DESEMBARGADOR; } 0=\text { JUIZ SUBSTITUTO })\end{array}$ & $49,53 \%$ & $30,33 \%$ \\
\hline UNANIMIDADE (1 = SIM; 0 = NÃO) & $44,19 \%$ & $59,47 \%$ \\
\hline $\begin{array}{r}\text { SUSTENTAÇÃO ORAL DO ADVOGADO DA EMPRESA } \\
(1=\text { PRESENÇA; } 0=\text { AUSÊNCIA) }\end{array}$ & $59,24 \%$ & $44,03 \%$ \\
\hline $\begin{array}{l}\text { ADIANTAMENTO DE RECURSOS } \\
(1=\text { PRESENÇA; } 0=\text { AUSÊNCIA })\end{array}$ & $90,44 \%$ & $42,51 \%$ \\
\hline STJ (1 = DECISÕES APÓS FEV./2006) & $56,19 \%$ & $40,53 \%$ \\
\hline
\end{tabular}


Observa-se, também, que quando o advogado de defesa da indústria fez uma sustentação oral dos seus argumentos no momento do julgamento, a probabilidade de a decisão ser favorável a ela aumentou de $44 \%$ a $59 \%$.

A principal alteração nas probabilidades deu-se quando houve adiantamento de recursos financeiros no momento em que o contrato foi realizado, nesse caso a probabilidade de o contrato ser mantido foi de $90 \%$ contra $42 \%$ quando não houve esse adiantamento.

Também foi constatado que, após fevereiro de 2006, quando foi emitida a primeira decisão do STJ sobre o conflito favorável à manutenção do contrato, a probabilidade de a decisão do Tribunal de Justiça segui-la foi de 56\% contra 40\% do momento anterior. Tal resultado indica o efeito sinalizador do tribunal.

\section{INSTABILIDADE GERADA NO AMBIENTE ECONÔMICO}

A partir da constatação do tipo de conflito ocorrido e do resultado das decisões judiciais, apresentaremos alguns dos efeitos gerados no ambiente econômico, relatados por produtores rurais e por representantes de empresas que atuam em Goiás.

$\mathrm{Na}$ pesquisa com os produtores, quando questionados sobre o número de contratos realizados nas safras 2002/2003, 2003/2004 e 2004/2005, notou-se uma redução de 44\% nos contratos de fixação de preço entre a safra de 2003/2004 e 2004/2005. Os contratos com adiantamento de insumos mantiveram-se constantes e os contratos com envolvimento de recursos financeiros também foram reduzidos, mas a variação foi menor. Não é possível afirmar se a redução de contratos de fixação de preços se deu devido ao evento das quebras contratuais, mas há indícios de que os fatos estejam relacionados, visto que a produção no Estado de Goiás aumentou 13,6\% nas safras mencionadas (Conab, 2007).

$\mathrm{Na}$ pesquisa, os produtores foram questionados quanto aos eventuais efeitos sofridos após o episódio das quebras contratuais. Entre os principais efeitos tem-se que cerca de metade dos produtores entrevistados declarou que, já na safra de 2005, houve maior exigência de garantias para crédito e custeio, 46\% deles disseram que passou a ser mais difícil negociar com a empresa e 30\% disseram que efetuaram menos contratos de venda antecipada.

Em uma reportagem do jornal Gazeta Mercantil (2004) afirmou-se que a operação de venda antecipada de soja respondia por quase $60 \%$ da compra de soja no Brasil e que, em 2003/2004, deixaram de ser entregues quase um milhão de toneladas, um prejuízo estimado em $\mathrm{R} \$ 1,2$ bilhão. $\mathrm{Na}$ mesma reportagem, foi comentado o fechamento do armazém da Cargill em Edeia, Goiás, caracterizado como "epicentro das ações judiciais que questionam os contratos de venda futura de soja" e a suspensão dessa modalidade de contrato pela empresa. Também foi citado que outras empresas finalizariam essa forma de contrato devido à incerteza jurídica. A reportagem indicava 
que Goiás seria o Estado mais afetado, visto que "entre 40\% e 50\% da safra goiana é comprometida com esse tipo de operação”.

Como foi demonstrado pelos resultados, o fato de a empresa ser goiana foi significante na decisão de primeira instância, diferentemente do que foi revelado na segunda instância. Supõe-se que o fato se deva à pressão social, sentida mais fortemente pelo juiz da Comarca. Uma decisão contrária à manutenção dos contratos pode levar indústrias a encerrarem suas atividades em determinada região, como aconteceu em Edeia, o que gera externalidades negativas para todos os agentes.

Em Itumbiara, a situação foi oposta, cem por cento das decisões foram favoráveis à manutenção do contrato. Essa pressão social pode ser traduzida em números para as duas cidades citadas. Analisando o Produto Interno Bruto (PIB) de Itumbiara e Edeia de 2004 vê-se que a agropecuária representa 7\% e 60\% do PIB, respectivamente. Por outro lado, o valor adicionado da indústria representa em Itumbiara 50\% do PIB. Além disso, Edeia, com uma população de 10.851 habitantes, foi o $16^{\circ}$ maior produtor de grãos do Estado de Goiás em 2005, ${ }^{8}$ Itumbiara foi o $19^{\circ}$ (Goiás, 2005 ; IBGE, 2004).

A maior parte das empresas entrevistadas declarou que não realizam mais contratos com preços prefixados de soja sem adiantamento de recursos e que apenas continuam com os contratos com antecipação de recursos financeiros e insumos, pois, segundo eles esses contratos tiveram menos casos de decisões favoráveis à sua anulação, fato confirmado na pesquisa empírica.

\section{CONCLUSÃo}

O contrato de compra e venda antecipada de soja mostrou-se incapaz de atuar como mecanismo eficiente para enfrentar grandes oscilações de preço. As empresas entrevistadas declararam não realizar mais contratos com preços prefixados de soja, apenas contratos com antecipação de recursos financeiros e insumos, porém, os critérios para crédito foram repensados. As garantias exigidas aumentaram, bem como o monitoramento da produção. Além disso, o crédito só é concedido àqueles empresários com reputação no mercado.

Em entrevistas, foi constatado que, desde o início da utilização desses contratos, os agentes negociaram sem que houvesse problemas relevantes, mas no momento da colheita das safras 2002/2003 e 2003/2004, o preço praticado no mercado spot estava muito mais alto do que o contratado, ao contrário do que aconteceu nos anos anteriores. Um choque externo, qual seja a grande demanda da China e a quebra da safra de soja norte-americana, afetou a relação contratual, tornando vantajoso, sob a percepção de alguns produtores, o rompimento do contrato. Alguns produtores preferiram os ganhos de curto prazo em detrimento aos ganhos de longo prazo que seriam resultantes da manutenção da relação com a indústria/trading. 
Muitos produtores, contudo, se sentiram prejudicados em relação à reação das empresas que, segundo eles, foi indiscriminada, atingindo todos os produtores, mesmo aqueles que sempre cumpriram seus contratos.

Mais relevante que o número de contratos quebrados foi a repercussão gerada a partir desse fato. A maior parte dos produtores entrevistados declarou que sentiu o efeito das quebras contratuais dos outros produtores. As consequências mais citadas foram: maior exigência de garantias para crédito e custeio; maior dificuldade para negociar com a empresa; e redução do volume de contratos de venda antecipada efetuados.

De acordo com produtores e indústrias, a redução no volume de contratos a termo deve-se às seguintes razões: (1) preço baixo da saca de soja, devido ao excesso de oferta; (2) expectativa do produtor de elevação de preços durante a safra, como aconteceu em 2003 e 2004; e (3) ocorrência de quebra ou descumprimento de contrato nas duas últimas safras.

Foi observado que as indústrias/tradings efetuaram, em 2005, menos contratos de compra antecipada de soja verde, quando comparado ao mesmo período do ano anterior. Não está claro se existe causalidade entre a insegurança jurídica devido às diferentes decisões dos tribunais, no entanto, em uma oficina de trabalho realizada com os agentes foi citado que, caso a decisões continuem a favor das rescisões contratuais, as empresas poderiam transferir suas atividades para outro Estado que lhes confiasse maior segurança jurídica.

O estudo revela que existe divergência sobre o entendimento do conflito entre primeira e segunda instâncias e entre as Câmaras Cíveis do Tribunal de Justiça. Os dados exemplificam o problema da imprevisibilidade no judiciário brasileiro, que causa um dilema para as organizações.

O contrato existe para reduzir incertezas, logo, o instrumento contratual, na forma como foi praticado, mostrou-se frágil, sobretudo, devido à instabilidade do ambiente institucional. A redução do número de contratos celebrados, as novas exigências de garantias para o cumprimento do contrato e o processo de seleção de produtores são estratégias privadas adotadas para reduzir privadamente o conflito, mas estas elevam o custo da transação para os dois agentes.

A forma pela qual a quebra de contratos é decidida nos tribunais gera impactos nas estratégias das organizações. O resultado da pesquisa é explicado pela teoria, que diz que quando as "regras do jogo" não são claras para os agentes há incerteza, o aumento dos custos de transação nas negociações e as sanções econômicas são relevantes. O estudo dá transparência ao fato de que o Judiciário influencia o ambiente de negócios, pois as suas decisões produzem efeitos que repercutem nas ações dos agentes privados. Ao decidir pela parte hipossuficiente, o juiz gera efeitos secundários que acarretam a diminuição dos contratos, dificultando a negociação futura para todos os agentes. As empresas ficaram receosas de negociar, uma vez que não puderam contar com a segurança jurídica de que o contrato seria cumprido. A falta de 
consideração dos efeitos econômicos de segunda ordem pode ser interpretada como "miopia econômica” do Judiciário.

: ARTIGO APROVADO (10/08/2010) : RECEBIDO EM 24/02/2010

\section{NOTAS}

1 Gostaríamos de expressar nosso agradecimento às instituições Tinker Foundation, Capes e Fapesp que, em momentos distintos, apoiaram financeiramente a realização desta pesquisa.

2 Traduzido para o português como "há que se cumprir os pactos" (Costa e Aquaroli, 2006, p. 359).

3 O problema não se restringe ao mercado de soja. Para outro exemplo veja Zylbersztajn e Nadalini (2005). Tomatoes and Courts: agro-industrial strategy in face of weak property rights. Working Paper Series.

4 Limitação do procedimento: em virtude da dificuldade na obtenção de um banco de dados de produtores de soja não foi possível obter uma amostra aleatória stricto-sensu. O banco de dados utilizado para a realização das entrevistas telefônicas foi composto de dados cedidos por empresas do setor. As entrevistas presenciais foram realizadas por meio do apoio da Federação da Agricultura do Estado de Goiás e de associações de produtores de grãos que propiciaram o contato com os produtores.

5 Em nossa análise foram consideradas apenas as apelações cíveis. Por questões metodológicas, as ações de embargos e agravos de instrumento não foram consideradas.

6 Em 19 das 161 Apelações Cíveis analisadas não foi possível identificar o "inteiro teor do Acórdão" das decisões, como o voto individual, além disso o argumento dos juízes não pôde ser conhecido nesses casos, elas foram retiradas da amostra $\mathrm{C}$, que contém 426 observações de votos de 42 juízes.

7 O software Stata permite o cálculo da probabilidade de sucesso para determinado valor da variável, ceteris paribus, por meio do comando $\mathrm{mfx}$ at ( ).

8 Em 2005, a maior produção de grãos foi do município de Jataí-GO.

\section{REFERÊNCIAS BIBLIOGRÁFICAS}

ALMEIDA, Luciana Florêncio. 2008. Ambiente Institucional e Contratos de Crédito Agrícola: Três Estudos Críticos. Tese (Doutorado em Administração). Programa de Pós-Graduação em Administração, Faculdade de Economia, Administração e Contabilidade, Universidade de São Paulo, São Paulo.

ARRUÑADA, Benito; ANDONOVA; Veneta. Jugdes' Cognition and Market Order. Working Paper n. 768. Barcelona: Universitat Pompeu Fabra, 2004. (Working Paper Series) Instituições de mercado e competência do judiciário. In: ZYLBERSZTAJN, Decio; SZTAJN, Rachel. (Org.) Direito \& economia: Análise econômica do direito e das organizações. São Paulo: Campus, 2005, p. 139, 140. BARZEL, Yoram. Economic Analysis of Property Rights. 2. ed. Cambridge: Cambridge University Press, 1997. 
COASE, Ronald Harry. The Nature of the Firm. Economica, n. 4, p. 386-405, 1937.

CONAB. Série Histórica de Produção. Safras de 1976/1977 a 2006/2007. 2007. Disponível em: < http://www.conab.gov.br >. Acesso em: 17 jun. 2007.

COSTA, Wagner Venezian; AQUAROLI, Marcelo. Dicionário jurídico. São Paulo: WVC, 2006.

DELGADO, Mario Luiz; ALVES, Jones Figueiredo. Questões controvertidas no Novo Código Civil. vol. 2. São Paulo: Método, 2006. (Série Grandes Temas de Direito Privado)

GAZETA MERCANTIL. Análises \& Cotações. Indústria restringe compras de soja. 28/09/2004. Disponível em: $<$ http: / /www.soja.agr.br/news/category_news.asp?IDCategory=15\&IDNews=727\#727>. Acesso em: 18 out. 2004. GOIÁS: Portal do Agronegócio. Goiás: Maiores produtores de Grãos em 2005. Anuário estatístico. 2005.

Disponível em: <http://www.agronegocio.goias.gov.br>. Acesso em: 1 nov. 2007.

INSTITUTO BRASILEIRO DE GEOGRAFIA E ESTATÍSTICA - IBGE. Informações estatísticas. Cidades. Produto interno Bruto 2004. Disponível em: <http://www.ibge.gov.br/cidadesat/>. Acesso em: 5 nov. 2007.

KLEIN, Benjamin. Contracts and incentives: The Role of Contracts Terms in Assuring Performance. In: WERIN, L and WIJKANDER, R. Contract Economics. Oxford: Blackwell, 1992.

Ministério da Agricultura e Pecuária e Abastecimento - MAPA. Soja: Principais países produtores 2007.

Disponível em: <www.agricultura.gov.br>. Acesso em 16 jun. 2007.

NORTH, Douglass. Institutions, Institutional Change and Economic Performance. Cambridge: Cambridge University Press, 1990, p. 3.

REALE, Miguel. Função social do contrato. 2004. Disponível em

<http://www.miguelreale.com.br/artigos/funsoccont.htm>. Acesso em: 15 jun. 2005.

SZTAJN, Rachel; GORGA, Érica. Tradições do Direito. In: ZYLBERSZTAJN, Decio; SZTAJN, Rachel. (Org.)

Direito \& economia: Análise econômica do direito e das organizações. São Paulo: Campus, 2005.

SANTOS, Antônio Jeova. Função social do contrato. Lesão e imprevisão no CC/2002 e no CDC. 2. ed. São Paulo: Método, 2004, p. 28.

TIMM, Luciano Benetti. Direito, Economia e a Função Social do Contrato. Revista do Direito Bancário e do Mercado de Capitais, 9, n. 33, p. 19, 15-31, 2006.

WOOLDRIDGE, Jeffrey. Introdução à econometria: uma abordagem moderna. São Paulo: Pioneira Thomson Learning, 2006, p. 523 e 524.

ZYLBERSZTAJN, Decio. Estruturas de governança e Coordenação do Agribusiness: uma aplicação da Nova Economia das Instituições. 1995. Tese (Livre Docência em Administração). Programa de Pós-Graduação em Administração, Faculdade de Economia, Administração e Contabilidade, Universidade de São Paulo, São Paulo. ZYLBERSZTAJN, Decio; FARINA, Elizabeth Maria Mercier Querido. Strictly Coordinated Food Systems: exploring the limits of the coasian firm. International Food and Agribusiness Management Review, Nova York, v. 2, p. 249-265, 1999.

ZYLBERSZTAJN, Decio; SZTAJN, Rachel (Org.) Direito \& economia: análise econômica do direito e das organizações. São Paulo: Campus, 2005.

Christiane Leles Rezende

Rua Valson Lopes, 101, sala S02 Rio Pequeno - 05360-020 São Paulo - SP - Brasil christianelapensa.org.br

Av. Professor Luciano Gualberto, 908, sala 180

Cidade universitária - 05508-900 São Paulo - SP - Brasil dezylberlausp.br
Pesquisadora-doutora do Centro de Conhecimentos em Agronegócios, Pensa

Decio Zylbersztajn

Presidente do Conselho do Centro de Conhecimentos em Agronegócios, Pensa Professor titular da Faculdade de Economia, Administração E Contabilidade, USP 
